\title{
Influence of the Madden-Julian Oscillation on East African rainfall. I: Intraseasonal variability and regional dependency
}

\author{
By BENJAMIN POHL* and PIERRE CAMBERLIN \\ Centre de Recherches de Climatologie, CNRS/Université de Bourgogne, Dijon, France
}

(Received 26 May 2005; revised 10 October 2005)

\section{SUMMARY}

The influence of the Madden-Julian Oscillation (MJO) on rainfall amounts over Equatorial East Africa (Kenya and northern Tanzania) is analysed for the period 1979-95 at the intraseasonal (pentad) time-scale. The two rainy seasons (March to May and October to December) are considered. Intraseasonal wet events in East Africa are embedded in large-scale zonal circulation anomaly patterns along the equator, showing distinct eastward propagation. It is further found that these 'wet' events display a clear phasing with respect to the MJO cycle. This phasing is expressed as out-of-phase variations between the Highland and the coastal areas. Such a pattern is suggested to reflect different rain-causing mechanisms. MJO phases leading to wet spells in the western (Highland) region are those associated with the development of large-scale convection in the Africa/Indian Ocean region. These events are unambiguously related to deep convection, fuelled by low-level westerly moisture advection. MJO phases leading to wet spells in the eastern (coastal) region are often those associated with overall suppressed deep convection in the Africa/Indian Ocean region. However, these phases induce moisture advection from Indian Ocean. The possible role of stratiform rainfall or relatively shallow convection in the coastal wet spells observed in this phase is discussed. The contrasting rainfall conditions found in the two regions for the two opposite MJO phases are strongly correlated with the pressure gradient between the Indian and Atlantic Oceans.

KEYWORDS: Convective rainfall Long rains Short rains Wet spells

\section{INTRODUCTION}

The Madden-Julian Oscillation (MJO) has been known for years to be the dominant mode of intraseasonal climate variability over the Indian and the West Pacific Oceans. The initial report (Madden and Julian 1971; 1972) depicts a periodicity of 40-50 days in the large-scale variations of upper- and lower-layer zonal wind, surface pressure and temperature at different levels of the troposphere. Schematically, the MJO may be seen as an eastward propagation, along the equator, of circulation anomaly cells, and convective cloud clusters associated with the ascending branch of these cells. The oscillation is known to be particularly developed over the tropical Indian Ocean; however, the potential contribution of the MJO to the variability of rainfall amounts over Equatorial East Africa (EEA: Kenya and northern Tanzania) has never been directly studied.

The EEA climate which constitutes the focus of the present study (Fig. 1), is characterized at the intraseasonal time-scale by the succession of wet and dry spells. Typically, a rainy season may be composed of three to four 10-day rainy periods, each liable to bring 100 to $150 \mathrm{~mm}$ of rain over the area (Kabanda and Jury 2000) and separated from each other by drier phases. The distribution of the rains within a season is as important for crops and yields as the seasonal rainfall amounts. The dependence on water resources locally is amplified by poverty, and by the role agriculture still plays in the economy. Drought years, such as 1984, 1996, 1998 and 2000, often lead to food shortages and possibly international food assistance. Even in years of more abundant rainfall, dry spells during the wet season may have significant impacts on crop yields. A dry spell occurring during the flowering phase has been shown to cause an estimated $72-75 \%$ reduction of maize yield on sandy soils in eastern Kenya (Barron et al. 2003).

\footnotetext{
* Corresponding author: Centre de Recherches de Climatologie, Sciences Gabriel, BP 27877, F21078 Dijon Cedex, France. e-mail: benjamin.pohl@u-bourgogne.fr
}

(c) Royal Meteorological Society, 2006. 


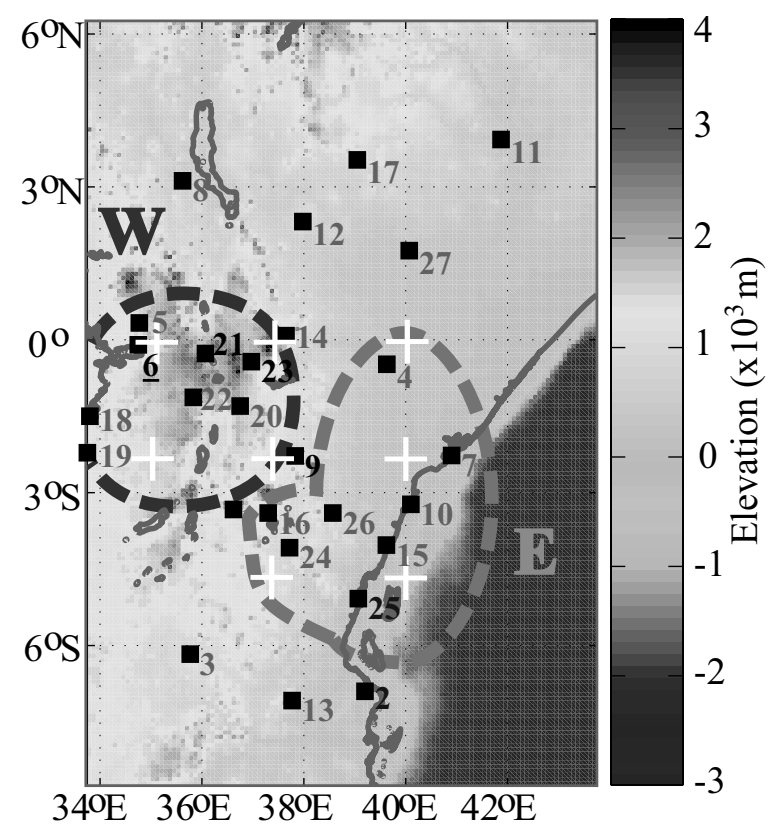

Figure 1. East Africa showing locations of the 27 rain-gauge stations (squares) and the topography (shading). Eastern (E) and western (W) rainfall regions, as defined in subsection 3(a), are enclosed by dashed lines. Plus signs indicate the grid points for satellite measurements of outgoing long-wave radiation used in the study.

The role played by the MJO on rainfall distribution and subsequent water stress for crops is yet to be determined.

Mpeta and Jury (2001) and Mutai and Ward (2000) identified eastward-propagating convective perturbations affecting the EEA region and generating rainy spells. Mpeta and Jury (2001) also observed a strong variability in outgoing long-wave radiation (OLR) satellite data, used to approximate tropical convection, occurring simultaneously with strong $850 \mathrm{hPa}$ zonal-wind anomalies; in most cases (62\%) these large-scale structures were seen to propagate west to east. Removing the El Niño Southern Oscillation (ENSO) signal, Mutai and Ward (2000) concluded that there is a relation between East African rainfall and convection cells propagating eastward along the equator, from the Gulf of Guinea up to the central Indian Ocean. Knutson and Weickmann (1987) also showed an OLR signal associated with the MJO over Africa. Pohl et al. (2005) in their classification of the most recurrent circulation anomaly patterns above and around the EEA region, found that several circulation types distinctly coincide with certain MJO phases. Matthews (2004) demonstrated that the MJO interacts with the West African monsoon during the boreal summer. In spite of the location of the EEA region between West Africa and the equatorial Indian Ocean, the latter being known to concentrate much of the MJO variance, the influence of the MJO on the Kenyan and north-Tanzanian climate at intraseasonal time-scales has never been determined to date; this is the aim of the present work.

\section{DATA AND METHODOLOGY}

\section{(a) Daily rainfall observations}

Daily rain-gauge records at nine stations in Tanzania and 18 in Kenya (see Fig. 1 for their locations) have been obtained from the Kenyan and Tanzanian meteorological 
services, augmented by some data from the African Desk of the Climate Prediction Center of the National Oceanic and Atmospheric Administration (NOAA). They are available for the period 1971-95. Details of the data and quality control are provided in Camberlin and Wairoto (1997) and Camberlin and Okoola (2003). Missing values are relatively rare $(1.3 \%)$. Pentad (5-day) values have been obtained by summing daily values. The annual cycle has been removed by subtracting, from each pentad of each year, the smoothed (15-day low-pass filtered) 25-year mean rainfall amount (1971-95) of the corresponding pentad. The region experiences two rainy seasons; thus we focus on the period from March to May (MAM, pentads 13-30) corresponding to the 'long rains', and that from October to December (OND, pentads 56-73) corresponding to the 'short rains'.

\section{(b) Estimations of atmospheric flows and convection}

This study also makes use of the National Centre for Environmental Prediction (NCEP) - Department of Energy R-2 Reanalysis (NCEP-2) fields (Kalnay et al. 1996; Kanamitsu et al. 2002). The present work uses the zonal $(u)$ and meridional $(v)$ components of the wind, air temperature, mean sea-level pressure (MSLP), geopotential height (all considered by Kalnay et al. 1996 to be 'most reliable') and the vertical wind component ( $w$; considered to be 'quite reliable'). Many researchers including Mutai and Ward (2000), Camberlin and Philippon (2002), Zorita and Tilya (2002) have used NCEP-2 data for various studies over the region; they have shown that they constitute a good approximation of the real atmospheric flows.

The NOAA OLR dataset (Liebmann and Smith 1996) is used as an indicator of convective precipitation, since it generally offers an accurate estimation of tropical convection (Mutai and Ward 2000; Mpeta and Jury 2001).

\section{(c) Australian Bureau of Meteorology's MJO indices}

Although Madden and Julian $(1971,1994)$ referred to their observation as 'the 40-50-day oscillation', the periodicity of the intraseasonal oscillation may in fact vary from 30 to 60 days, i.e. it may double from one cycle to another. This nonstationarity causes the signal to become out-of-phase when a temporal lag composite analysis is applied. As a result, the anomaly fields may appear quite inconsistent both spatially and temporally, and the average hides a huge diversity of cases. Therefore, as an alternative, we use the MJO indices from the Australian Bureau of Meteorology Research Centre. These indices are based on the approach followed by Wheeler and Hendon (2004, hereafter WH04). The first two empirical orthogonal functions (RMM1 and RMM2; WH04) of a principal component analysis (PCA) applied to unfiltered zonal winds at 850 and $200 \mathrm{hPa}$, and OLR fields after removing the ENSO signal, are in phase quadrature. They describe the MJO activity over the Indian and Pacific basins, respectively, and the eastward propagation of the main large-scale anomaly patterns.

The general methodology used in this paper is based on composite anomalies over the MJO cycle. We divide the MJO into eighths of cycle depending on the location of the MJO convective clusters within the Tropics. To illustrate this, Fig. 2(a) displays the MJO activity between December 1987 and April 1988 as an example. This period is characterized by anomalously high MJO activity (Matthews 2000). By projecting the daily fields on RMM1 and RMM2, it is possible to describe the phase in the MJO cycle as well as the amplitude of the signal. The phase is expressed in radians (angle $\alpha$ ) and denotes the region over which the MJO-associated large-scale convection is at its maximum. For instance, at phase $3 \pi / 2$ large-scale convection is enhanced 

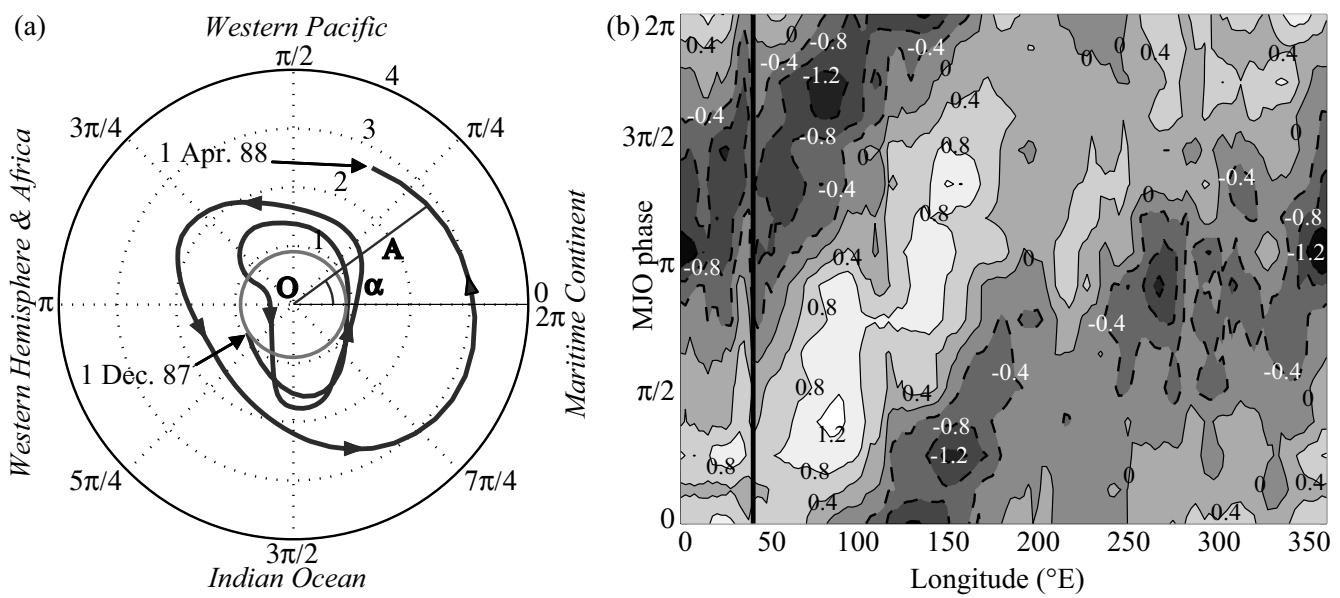

Figure 2. (a) Example of Madden-Julian Oscillation (MJO) activity from 1 December 1987 to 1 April 1988, as described by indices from the Australian Bureau of Meteorology Research Centre (Wheeler and Hendon 2004). The time-evolution of MJO activity is depicted by angle $\alpha$ and amplitude $A: \alpha$ depends on the location of the main convective-cloud clusters (e.g. between the Maritime Continent and the western Pacific on 1 April 1988); $A$ depends on the intensity of the wind and outgoing long-wave radiation (OLR) anomalies associated with the MJO. (b) MJO phase-longitude diagram of OLR anomalies as standard deviations from the mean, with seasonal variations removed, in the $10^{\circ} \mathrm{N}-10^{\circ} \mathrm{S}$ belt for the aggregate of the two periods March to May and October to December from 1979 to 2002 . Only moderate to strong MJO periods with $A>0.9$ were retained. The OLR grid points were 20- to 75-day band-pass filtered and standardized for each longitude. The East African meridian $\left(40^{\circ} \mathrm{E}\right)$ is shown as a vertical thick line. Negative OLR anomalies (enhanced convection) are shown by dark shading and dashed lines.

over the central Indian Ocean, and suppressed over the western Pacific (for details, see the mean OLR anomalies found at each phase and each longitude in Fig. 2(b) and WH04). The amplitude $(A)$ of the MJO signal is measured by the distance between each point and the origin point $\mathrm{O}$. The MJO index (daily or pentad average) is, therefore, expressed in polar coordinates. Such an approach to the MJO reduces every cycle to a constant angular period (strictly equal to $2 \pi$ radians), and thus eliminates the temporal non-stationarity of the period. Similar indices have been used in many previous works (e.g. Matthews 2000; Hsu and Lee 2005). It must be remembered that every $\pi / 4$ period, corresponding to one eighth of the total cycle, approximately represents a 6-day-period (in the case of a 48-day total MJO cycle, which constitutes a realistic median value).

\section{RESUlts}

\section{(a) Intraseasonal fluctuations of EEA rainfall}

As an introduction to the analysis of intraseasonal rainfall variability in EEA, this section is based on raw (unfiltered) rainfall records. Figure 3 presents pentad rainfall recorded at a sample station (Kisumu) for the three long-rains seasons from 1979 to 1981 taken as examples. This station is located in western Kenya on the shore of Lake Victoria, at $1146 \mathrm{~m}$ altitude and close to the equator (Fig. 1, station 6). Three distinct wet phases are found in 1979, separated by drier periods lasting about 2025 days. Similar alternations of wet and dry phases occur in 1980 and 1981, though the intervals between the wet spells tend to be longer. Well-defined intraseasonal variability is also conspicuous for all the stations located in the East African Highlands (see Fig. 1 for location) in both the long and the short rains; also the rain-gauge records in this area clearly exhibit in-phase variability (not shown). 


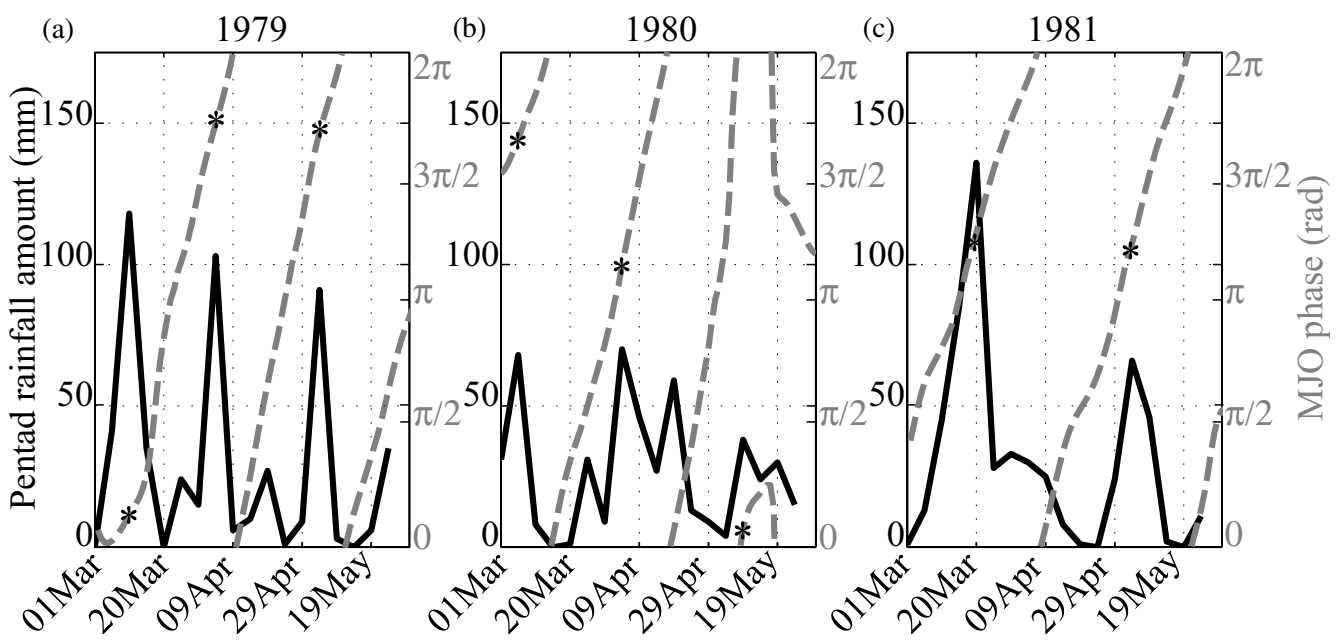

Figure 3. Pentad rainfall amounts at Kisumu, Kenya (station 6 in Fig. 1), in the Western region (solid line and left-hand $y$-axis) and corresponding Madden-Julian Oscillation (MJO) phase as defined in Fig. 2 (dashed lines and right-hand $y$-axis), for the long rains seasons of: (a) 1979, (b) 1980, and (c) 1981. Asterisks denote the MJO phase during the rainfall peaks.

The wet spells recorded at Kisumu do not occur randomly in regard to the MJO activity. They usually correspond to a preferential phase of the oscillation. The rainfall peaks tend to cluster in the $\pi$ to $2 \pi$ MJO phases (asterisks in Fig. 3). Similarly the dry spells tend to cluster from 0 to $\pi$. Observations from other Highland stations confirm that the first half of the MJO cycle is often associated with dry conditions and the second part with heavy rainy spells. The phase-locking between the Highland wet spells and the MJO suggests that the latter significantly contributes to intraseasonal rainfall variability in the region.

In order to assess to what extent the above remarks can be generalized, and to describe the spatial patterns of intraseasonal rainfall variability in EEA, a PCA was applied to the 27 unfiltered (but with seasonal variations removed) rain-gauge time series at the pentad time-scale, over the combined MAM and OND seasons. Note that the same analysis carried out on band-pass filtered (20-75 days) rainfall data yielded similar results (not shown). The first two PCs, PC\#1 and PC\#2, explaining about 20 and $10 \%$ of the variance, respectively, are retained (Fig. 4), in accordance with the scree-test results.

PC\#1 (Figs. 4(a) to (c)) depicts in-phase rainfall variations over EEA, and isolates pentads in which quasi-uniform dry or wet conditions are experienced in the region. These pentads were then extracted using the percentile method, in which 'wet' events have PC\#1 scores above the 80 percentile, and dry events have PC\#1 scores below the 20 percentile. They were next plotted against the MJO phase and amplitude (Figs. 4(b) and (c)). The wet events do not occur at preferential MJO phases (44\% occur from phase 0 to $\pi$ and $56 \%$ from $\pi$ to $2 \pi$ ). The same applies to dry events: $55 \%$ of them occur from 0 to $\pi$ and $45 \%$ from $\pi$ to $2 \pi$. These in-phase rainfall events over EEA are thus unrelated to the intraseasonal oscillation. A detailed analysis of PC\#1 (not shown) reveals that it mainly relates to abnormally early or late rainy season onsets, a result consistent with Camberlin and Okoola (2003). PC\#1 also exhibits a strong interannual component; therefore, it is not discussed further in this study. 
(a) Rainfall PC\#1 20.0\% var.

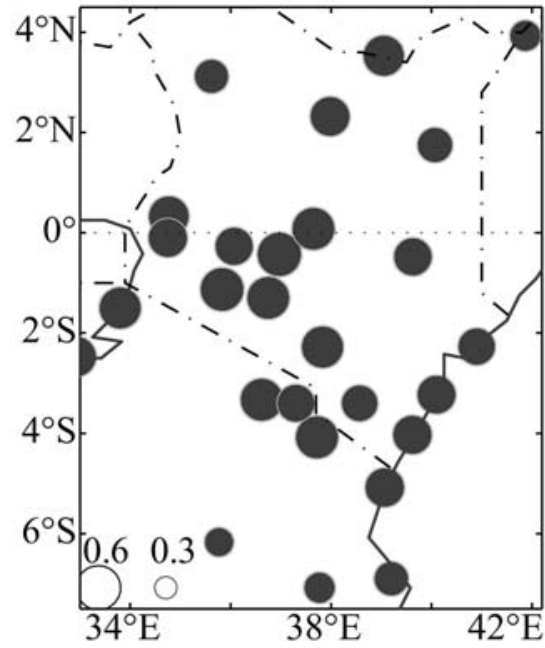

(b) PC\#1 scores $>$ prctile 80

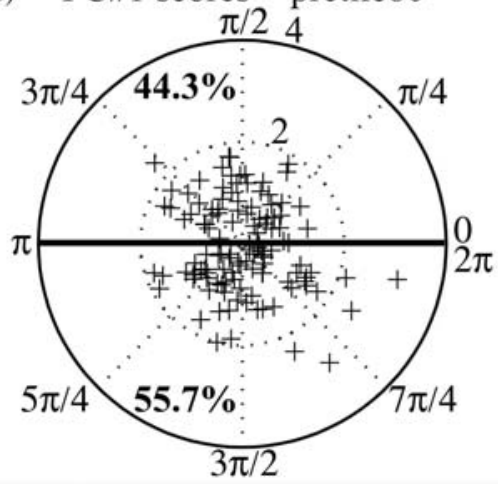

(c) PC\#1 scores $<$ prctile20

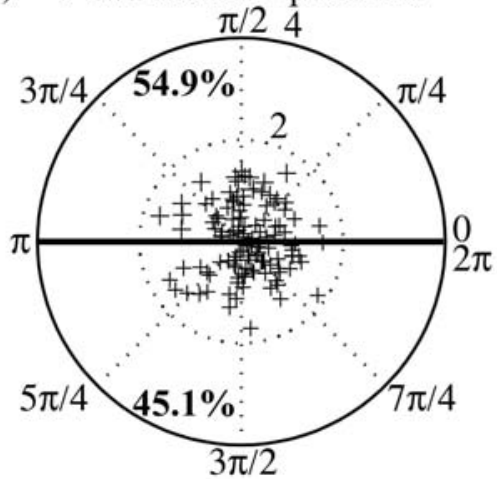

(d) Rainfall PC\#2 9.8\% var.

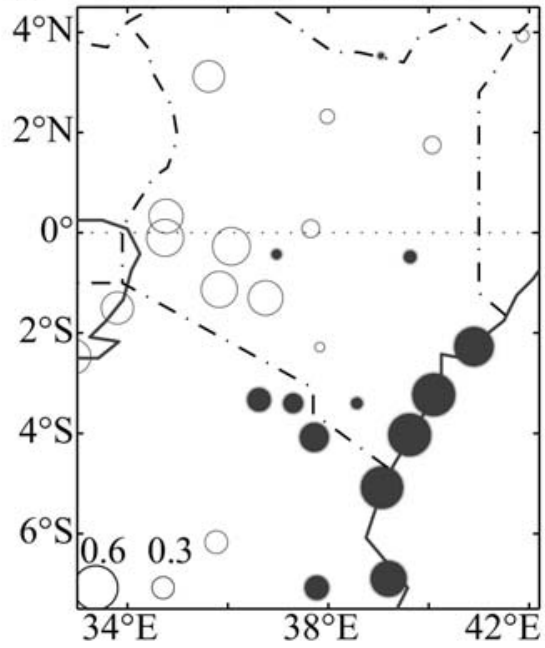

(e)

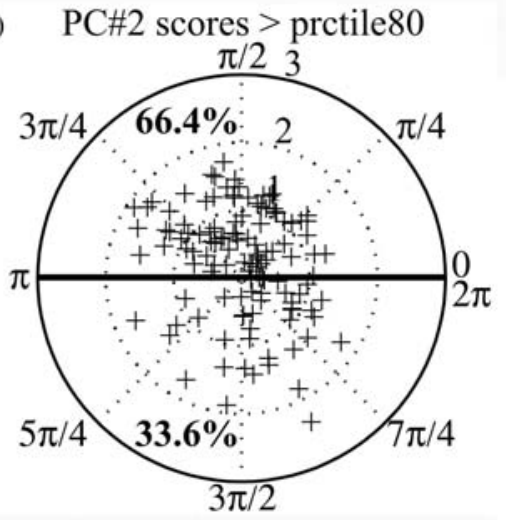

(f)

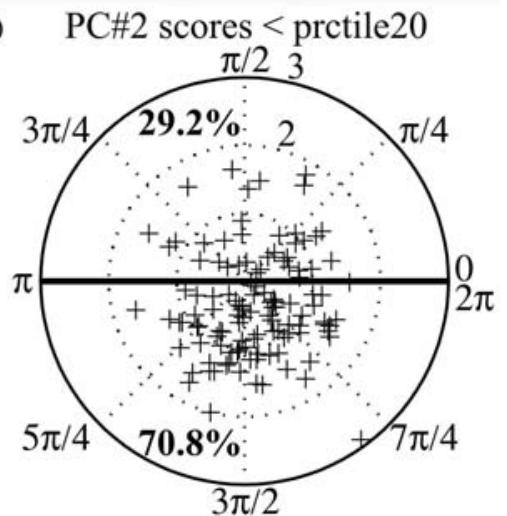

Figure 4. Principal component (PC) analysis applied to pentad rain-gauge totals with seasonal variations removed, for the aggregate of the two periods March to May and October to December 1979-95: (a) PC\#1 loading patterns; (b) distribution with respect to the Madden-Julian Oscillation (MJO) phases of the highest scores (above 80 percentile) for PC\#1; (c) as (b) but for the lowest scores (below 20 percentile); (d), (e) and (f) are as (a), (b) and (c), respectively, but for PC\#2. In (a) and (d) black circles show positive correlations with the respective PCs; white circles denote negative correlations. The area of each circle is proportional to the absolute value of the correlation coefficient (see legend in the lower-left of each frame). 

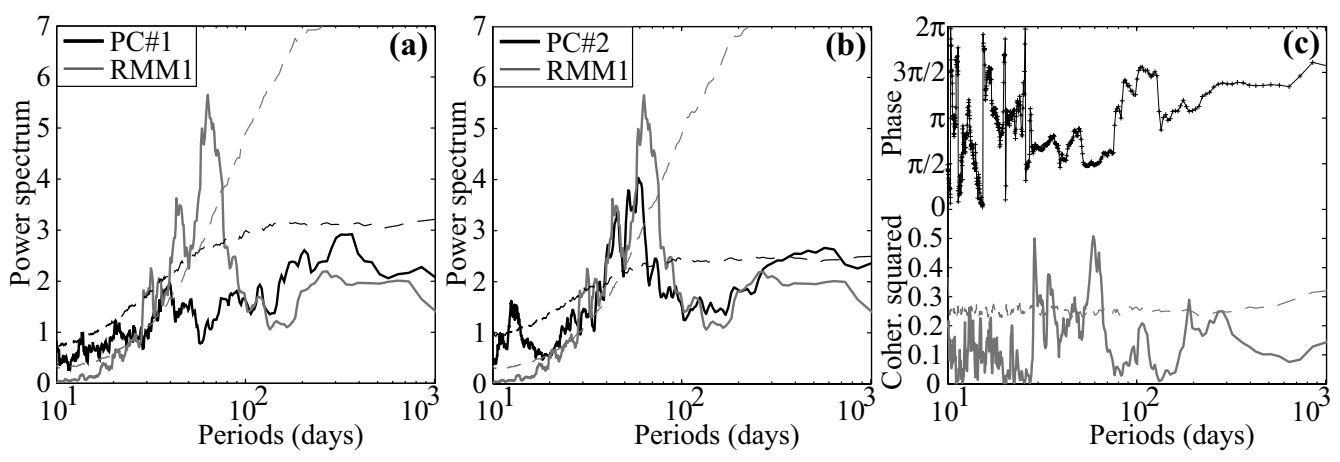

Figure 5. Spectrum and cross-spectrum analysis of rainfall principal components (PCs) and the index of the first empirical orthogonal function (RMM1; Wheeler and Hendon 2004). All analyses are carried out on normalized data for the aggregate of the two periods March to May and October to December 1979-95, with other months padded with zeros. (a) Power spectrum for rainfall PC\#1 (solid black line) and RMM1 (solid grey line); dashed lines indicate the $95 \%$ confidence level according to 1000 random time series obtained as permutations of the original time series, and having the same lag-1 serial correlation. (b) As (a) but for rainfall PC\#2. (c) Crossspectrum of rainfall PC\#2 and RMM1; the solid grey line gives the squared coherence, with the dashed line indicating the $95 \%$ significance level computed as in (a); the solid black line with plus signs gives the phase

in radians.

PC\#2 (Figs. 4(d) to (f)) displays a rainfall dipole consisting of two sub-regions. The first corresponds to the East African seashore in the east (positive correlations with PC\#2), the second sub-region corresponds to the Highlands in the west (Rift Valley and Lake Victoria, negative correlations). Pentad scores above the 80 percentile and below the 20 percentile were again extracted as for PC\#1. Both display a phase-locking to the MJO cycle (Figs. 4(e) and (f)). High positive scores are associated with wet conditions on the coast and dry conditions in the Highlands; $66 \%$ of these events occur between phase 0 and $\pi$, while only $34 \%$ are recorded between $\pi$ and $2 \pi$. An opposite distribution is found for negative scores, which correspond to dry (wet) conditions in the east (west): $71 \%$ occur from phase $\pi$ to $2 \pi$, and only $29 \%$ from 0 to $\pi$. Wet conditions over the Highlands tend to occur when large-scale MJO-related convective activity has reached tropical Africa and the Indian Ocean basin, which is quite consistent with the pattern displayed in Fig. 2. These results, which extend those obtained for Kisumu (Fig. 3), provide evidence that $\mathrm{PC \# 2}$ is not randomly distributed over the MJO phases.

As confirmation, power spectrum analyses of both standardized PC time series were carried out, after padding the dry-season months (January-February and JuneSeptember) with zeros. While PC\#1 does not exhibit any significant spectral peak (Fig. 5(a)), PC\#2 shows two highly significant (95\% level) peaks (Fig. 5(b)). The first peak corresponds to quasi-fortnightly variations, and the second to 30- to 60-day oscillations. The coherence with RMM1 (Fig. 5) spectral peaks in the MJO range is very clear, as demonstrated by cross-spectrum analysis (Fig. 5(c)). The same results are obtained for RMM2 with a $\pi / 2$ phase shift (not shown).

In order to show the large-scale wind anomaly patterns in which the EEA intraseasonal rainfall fluctuations are embedded, the zonal components of the winds at 850 and $200 \mathrm{hPa}$ along the equator (from NCEP-2) are correlated with the PC\#2 time series. In order to reduce the effects of high-frequency noise and interannual variability, the PC\#2 scores were filtered using a Butterworth band-pass filter to retain the 20- to 75-day signal. Wang and Xu (1997) used a similar filter in their study of low-frequency oscillations in the Indian and East Asian summer monsoons, and its efficiency to retain the MJO signal was discussed in Fink and Speth (1997). 
Figure 6 displays a time-longitude pattern of the lagged correlations between filtered PC\#2 and filtered zonal winds. A Monte Carlo technique, based on 1000 time series obtained from a random resampling of the original time series, with the same autocorrelation, gave a $95 \%$ confidence level for the correlations at 0.11 . The same significance threshold was obtained after computing the estimated reduction in degrees of freedom due to autocorrelation and filtering (Der Mégréditchian 1992). For zero-lag, i.e. for synchronous correlations, negative values are found between 10 and $40^{\circ} \mathrm{E}$ for the lower levels $(850 \mathrm{hPa})$, indicating that wet (dry) spells over the EEA Highlands (EEA coast) tend to be concomitant with westerly anomalies over equatorial Africa. On the other hand, positive correlations from $0^{\circ}$ to $60^{\circ} \mathrm{E}$ in the upper layers $(200 \mathrm{hPa})$ denote large-scale easterly anomalies over Africa and the western Indian Ocean. Lagged correlations (Fig. 6) unambiguously show an eastward propagation of the large-scale zonal wind anomalies in which the wet spells are embedded. The opposite sign between lower and upper layers can be interpreted as a characteristic of a large-scale cellular zonal circulation at the equatorial latitudes. These two results fully correspond to some of the best-known features of the MJO (Madden and Julian 1994). They also strongly reinforce the hypothesis that the MJO is implicated in the oscillation in the EEA intraseasonal rainfall fluctuations.

However, these results are based on the second PC, which depicts a local (eastwest) modulation of the rains, whereas the dominant PC displays in-phase rainfall fluctuations and is relatively independent of MJO activity. It is, therefore, questionable to what extent the latter influences the total variations of rainfall amounts. In view of this, the following section considers regional rainfall indices instead of PCs, with the aim of assessing the detailed response to each MJO phase.

\section{(b) Rainfall anomaly patterns associated with the MJO phases}

Since EEA does not appear as a homogeneous area at the intraseasonal time-scale, the wet spell distribution over the intraseasonal cycle has been analysed for each of the 27 rain-gauges (not shown). This enabled us to define two spatially consistent regional indices, which basically reflect the east-west differences in rainfall variations as displayed in subsection 3(a) and also found in Pohl et al. (2005). The first index corresponds to the Highlands (western part of the domain, W on Fig. 1), and the second index to the coastal and other eastern stations (E on Fig. 1). Each rainfall index simply consists of the average pentad rainfall from eight stations located within the respective region. The OLR grid points coinciding with the west and east regions (four grid points in each case; see Fig. 1) are also spatially averaged to constitute two OLR indices.

All moderate to strong MJO events were selected, by extracting the pentads having an MJO amplitude greater than 0.9 (solid inner circle on Fig. 2). This threshold roughly corresponds to the mean MJO amplitude over the period (0.89). The implications of this arbitrarily defined threshold will be discussed below. For the MAM and OND seasons from 1979 to 2002 this results in the selection of 435 pentads (about $50 \%$ of the initial sample). The MJO cycle has then been divided into eight different phases, each of $\pi / 4$ radians, as displayed in Fig. 2(a). Composite analyses are then applied on raw (unfiltered) atmospheric fields and rainfall data, by computing the mean anomaly value for each of the eight MJO phases. The composite rainfall anomalies in the Highlands and on the coast are analysed separately (Fig. 7). 


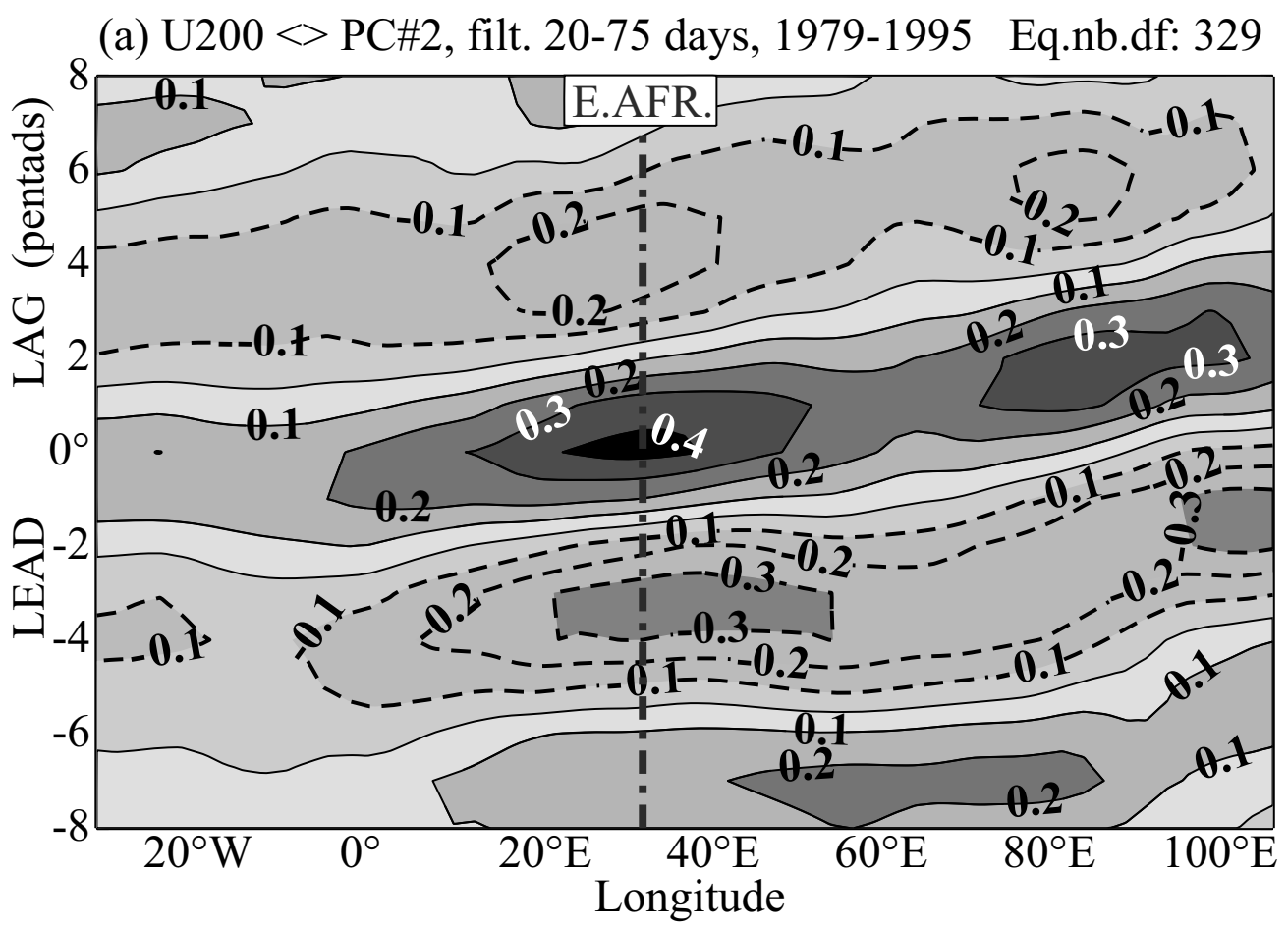

(b) U850 <> PC\#2, filt. 20-75 days, 1979-1995 Eq.nb.df: 329

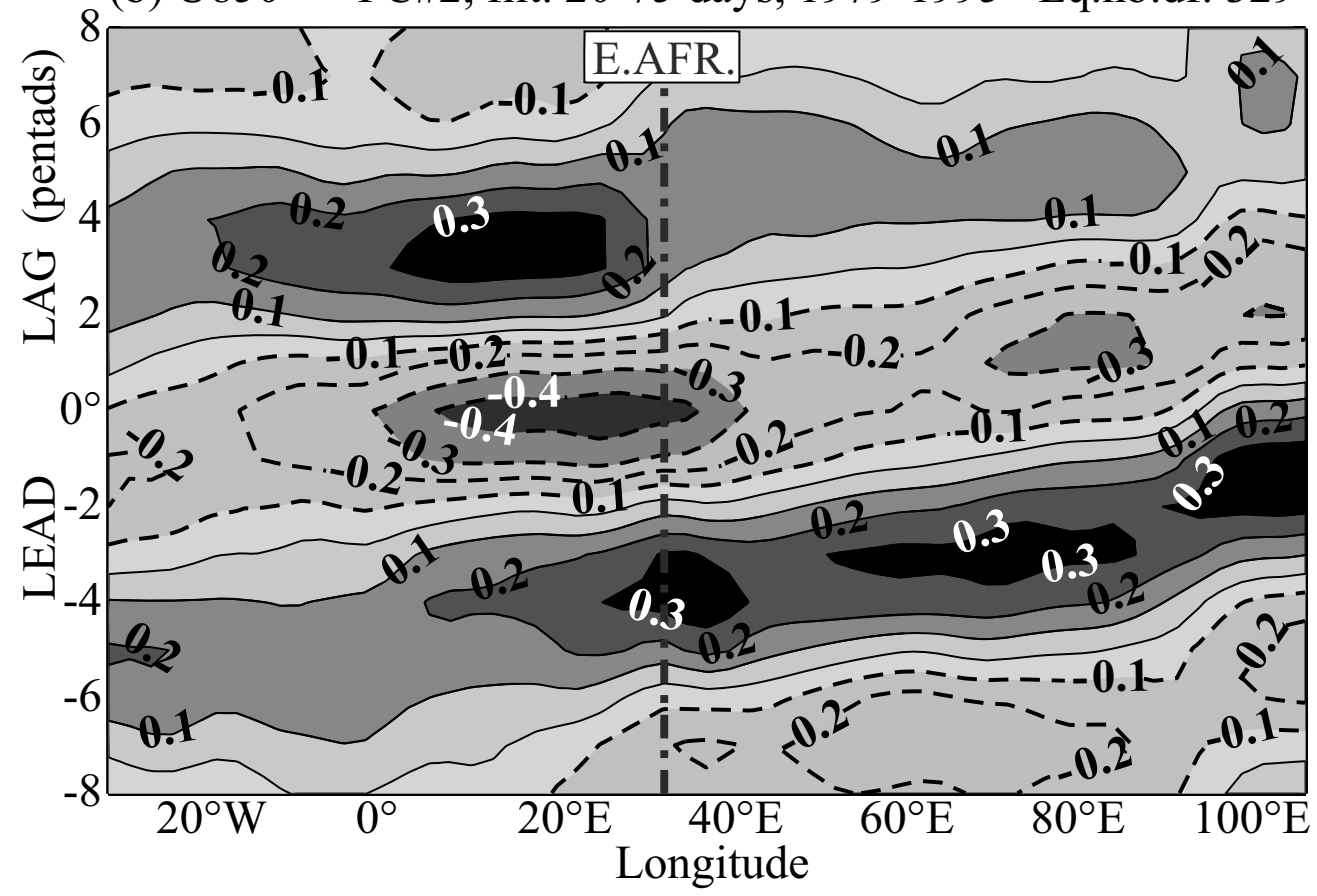

Figure 6. Lagged correlations between the 20- to 75-day filtered principal component, PC\#2, scores and similarly filtered (a) $200 \mathrm{hPa}$, and (b) $850 \mathrm{hPa}$ zonal winds along the equator $\left(2.5^{\circ} \mathrm{N}-2.5^{\circ} \mathrm{S}\right)$, for the aggregate of the two periods March to May and October to December 1979-95. Solid lines denote positive and dashed lines negative correlations. Given an equivalent number of degrees of freedom of 329 (i.e. taking into account the autocorrelation of the filtered series) correlation values higher than 0.11 are significant at the $95 \%$ confidence level. 

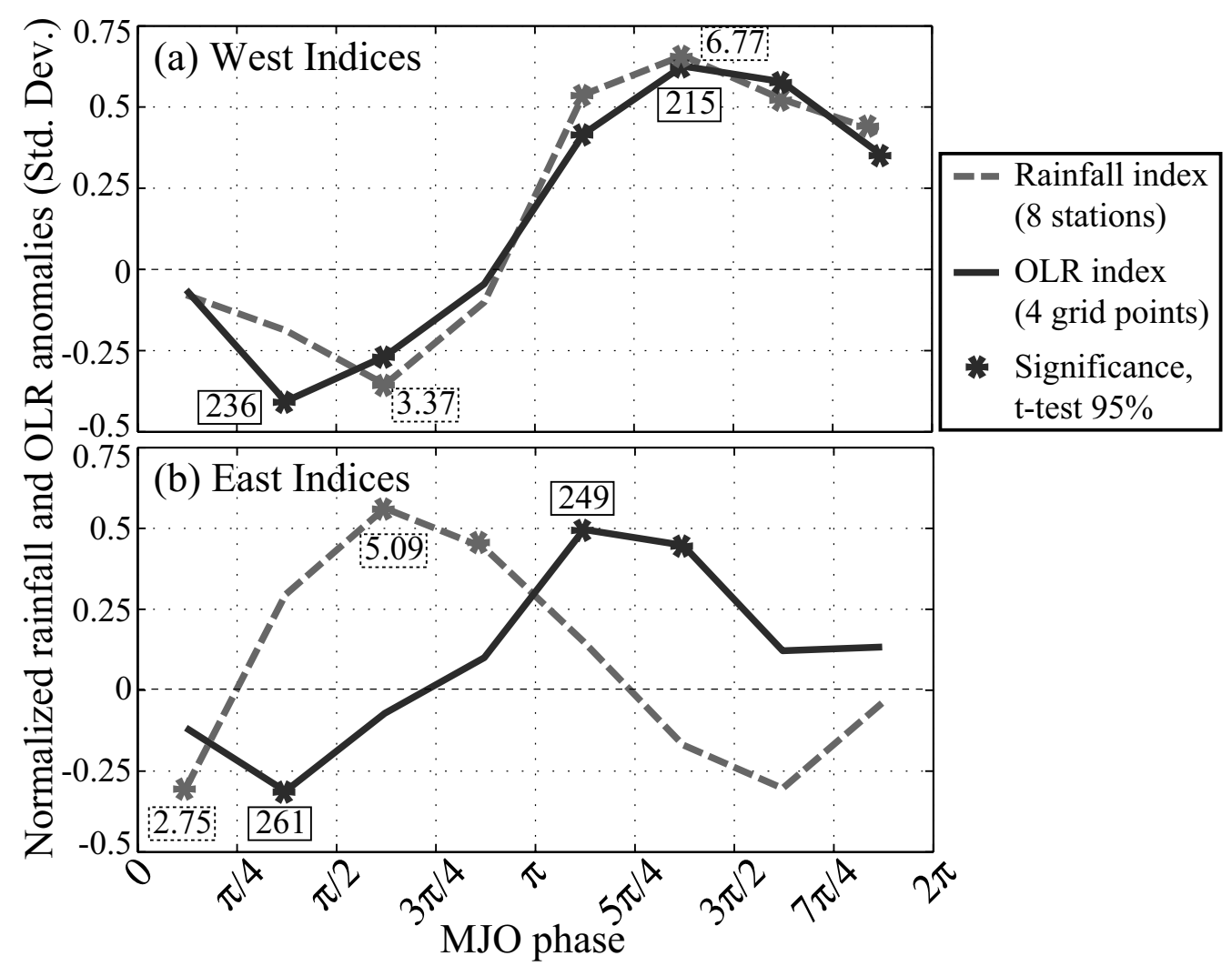

Figure 7. Mean rainfall and outgoing long-wave radiation (OLR) anomalies compared for each Madden-Julian Oscillation (MJO) phase: (a) western (W) regional rain-gauge measurements and OLR indices (area as defined in Fig. 1); (b) as in (a) but for the eastern (E) rain-gauge and OLR indices. Anomalies are calculated after removal of the annual cycle and standardized to allow comparison. OLR anomalies have been multiplied by -1 in order to examine the relationships with precipitation amounts. Corresponding raw values are also indicated $\left(\mathrm{mm}^{-1 a y}{ }^{-1}\right.$ for rainfall; $\mathrm{W} \mathrm{m}^{-2}$ for OLR). Asterisks denote significant rainfall (grey) and OLR (black) anomalies ( $t$-test, $95 \%$ level).

(i) The Highland rainfall index exhibits a unimodal pattern (Fig. 7(a)), with minimum rainfall shortly before phase $3 \pi / 4$ and maximum rainfall around $3 \pi / 2$. Both anomaly peaks are significant at the $95 \%$ level according to Student's $t$-test. For the positive rainfall anomalies four consecutive phases exhibit significant anomalies. All the stations included in this index display consistent results (not shown). The same analysis applied on raw (unfiltered) rainfall time series makes it possible to quantify the rainfall amount recorded during each of the phases: for the Highland region the daily amounts vary from $3.4 \mathrm{~mm} \mathrm{day}^{-1}(3 \pi / 4)$ to $6.8 \mathrm{~mm} \mathrm{day}^{-1}(3 \pi / 2)$. The corresponding OLR anomalies appear very consistent with the rainfall anomalies, leading to the hypothesis that enhanced deep convection (low OLR; note the reversed scale on Fig. 7(a)) is found concomitantly with precipitation maxima over the Highlands. The raw OLR values vary from $236 \mathrm{~W} \mathrm{~m}^{-2}$ during the dry period to $215 \mathrm{~W} \mathrm{~m}^{-2}$ during the wet period. The latter value is below the OLR threshold generally accepted for active convective systems (e.g. $220 \mathrm{~W} \mathrm{~m}^{-2}$ over the tropical regions according to Gunn et al. (1989)).

(ii) The East African coast and parts of nearby plains and lower slopes display rainfall anomalies for the different MJO phases (Fig. 7(b)) which are almost out-of-phase with 
those of the Highlands. Significant positive anomalies occur during the phases $\pi / 2$ to $\pi$, i.e. those associated with negative anomalies in the Highland region. This result is consistent with subsection 3(a), which was based on the analysis of PC\#2. However, the absolute values are not as large as in the western region (raw rainfall amounts vary from $2.8 \mathrm{~mm} \mathrm{day}^{-1}$ at zero phase to $5.1 \mathrm{~mm} \mathrm{day}^{-1}$ at $\pi / 2$ ) and $95 \%$ significance is reached only at these two phases, as well as at phase $3 \pi / 4$. In addition, the OLR anomaly pattern tends to be unrelated to that of rainfall (Fig. 7(b)): maximum OLR $\left(261 \mathrm{~W} \mathrm{~m}^{-2}\right.$ ) is found one phase after minimum rainfall, and low OLR at phases up to $5 \pi / 4$, at a time when the positive rainfall anomalies have already vanished. The OLR pattern for the eastern region is actually more in accordance with that of the western region (Fig. 7(a)), though its amplitude is smaller. In addition, the raw OLR values for the eastern region vary from 261 to $249 \mathrm{~W} \mathrm{~m}^{-2}$ depending on the phase, and are significantly higher than most deep convection thresholds. These findings suggest that the eastern rainfall anomalies associated with MJO activity result from precipitation events that may not be of deep convective origin. The separate study of the MAM and OND seasons as two different samples (not shown) further indicates that the western region rainfall peak $(3 \pi / 2)$ can be found during the two East African rainy seasons, whereas the eastern region peak $(\pi / 2$ to $\pi$ ) only exists during the long rains season.

In order to test whether rainfall anomalies are consistently discriminated by the different MJO phases, analyses of variance (anova) are performed on the OLR and rainfall unfiltered indices for both sub-regions. Both west indices are significantly discriminated (i.e. intra-phase variance is significantly lower than inter-phase variance) at a confidence level higher than $99.9 \%$. The discrimination of the east indices by the MJO phases is not as good (94.8\% and $98.2 \%$ confidence levels for OLR and rainfall, respectively). The influence of the MJO on EEA rainfall is therefore considered to be highly consistent in the Highlands, but more uncertain in the coast region.

It was then tested whether the value retained as a threshold for the MJO signal (0.9, Fig. 2) was impacting on these results. Higher thresholds (1.1 to 1.3) tend to be associated with higher rainfall generally over the whole EEA region at $3 \pi / 2$ in the MJO cycle. In particular, the negative anomalies recorded at this phase on the coast tend to reduce to zero, or even become positive, under strong MJO activity conditions. Corresponding OLR values also become lower over the region. It is, therefore, suggested that regional-scale deep convection is enhanced over the area when the MJO signal is stronger. It must, however, be remembered that such events are quite rare: $45 \%$ of the pentads experience an MJO amplitude higher than 0.9, but only $31 \%$ (19\%) an amplitude higher than $1.1(1.3)$.

To summarize: a moderate to strong MJO event is first accompanied, over East Africa, by a marked drying up in the western Kenya Highlands, in association with wet conditions in the east, at the time when large-scale convection peaks in the Pacific Ocean. Then, as the MJO propagates eastward, rainy conditions develop in the west whereas the east becomes drier. The unexpected rainfall response found in the east, associated with a different OLR pattern, may reflect rainfall events not associated with deep convection. The analysis of associated atmospheric dynamics will help to support this hypothesis.

\section{(c) Atmospheric dynamics and rain-causing mechanisms}

In order to determine the origins of the MJO-related rainfall anomalies over EEA, wind, MSLP, geopotential height and OLR fields have been considered. The methodology still consists of separating the data into composites discriminating between the 
different phases of the moderate to strong MJO cycles. For a region extending from the Atlantic to the Indian Ocean, vertical cross-sections along the equator for each phase are first presented, and then a closer scrutiny of the key phases is provided.

Circulation anomalies in relation to the MJO influence are displayed by combining zonal wind and vertical velocity, both unfiltered and with seasonal variations removed (Fig. 8). The Hotelling $t^{2}$-test (the multivariate generalization of the $t$-test; see Von Storch and Zwiers (1999) for details) is used to assess statistical significance. As previously noted, a 6-day range typically separates two consecutive phases in the case of a 48-day MJO cycle. Focus here is on the phases associated with significant rainfall anomalies on the EEA coast or Highland regions (as displayed in Fig. 7).

Starting from phases $\pi / 2$ to $\pi$ (leading to abnormally abundant rainfall amounts on the coast-Figs. 8(c) and (d)), anomalous easterlies and upward motion are observed at lower- and mid-levels over the Indian Ocean and nearby EEA, while weak subsidence is found over the Highlands. Strong westerly anomalies occur in the upper troposphere consistently from 30 to $80^{\circ} \mathrm{E}$. The observed upward motion off the Kenyan coast does not seem to result directly from an orographic forcing. However, the very weak OLR anomalies over EEA at this phase (Fig. 7(b)) are not in accordance with the above normal rainfall amounts over the coastal region.

At phase $\pi$ to $5 \pi / 4$ (Fig. 8(e)), upper westerly anomalies start to weaken, and upper-level horizontal divergence develops over Equatorial Africa. Such a pattern is a distinctive feature of the upper-tropospheric anomalies associated with MJO events (Knutson and Weickmann 1987; Madden and Julian 1994; Salby and Hendon 1994). At $5 \pi / 4$ (Fig. 8(f)), upper-tropospheric zonal wind anomalies reverse, and strong upward motion develops over the Highlands (Figs. 8(f) and (g)), i.e. only once the upperlayer zonal anomalies have become easterly. This is consistent with the above results showing that this is the time of maximum convection and rainfall over the Highlands. The vertical cross-section also displays lower- to mid-layer westerly anomalies over Central Africa. These conditions in the zonal wind appear as a key feature for ascent to develop over the whole depth of the troposphere. Note that these upward motion anomalies, and associated convection, tend to persist at the longitudes of EEA while lowerlevel convergence and upper-level divergence have already shifted eastward (not shown), i.e. from $5 \pi / 4$ to $7 \pi / 4$.

To summarize the analysis of the cross-sections: positive rainfall anomalies are observed over the Highlands at the phases associated with lower-layer westerly anomalies over central Africa and deep upward motion (denoting deep convection) over the Highlands; on the coast wet conditions relate to lower-layer easterly anomalies over the equatorial Indian Ocean, and no evidence of deep convection is found at this time. These results are consistent with those obtained from the PCA applied on rain-gauge time series (Figs. 4 and 6). While in the upper-troposphere there appear simple, planetary-scale MJO-associated wind anomalies, lower-tropospheric winds and vertical motion display more complicated patterns. Therefore, the two key phases which emerge from the analysis (i.e. when the ascending motion anomalies are located along the East African coast and the Highlands, respectively) are selected for further mapping and discussion.

The first key MJO phase, from $\pi / 2$ to $\pi$, corresponds to wet events on the coast and anomalous low-level easterlies over the western Indian Ocean (the $\pi / 2$ to $3 \pi / 4$ phase is presented in Figs. 9(a) to (d), as an example). At this phase of the MJO cycle, convection is mainly suppressed over the Indian Ocean, as demonstrated by the positive OLR anomalies in Figs. 2(b) and 9(d). Note also over the Highlands the isolated pocket of positive OLR anomalies, in agreement with the dry conditions that prevail at this time. 
(a) 0 to $\pi / 4[68]$

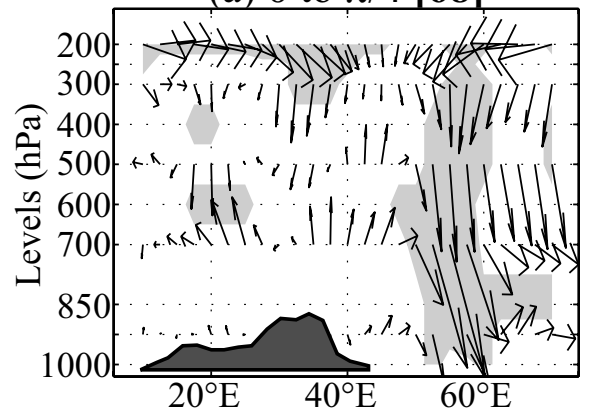

(b) $\pi / 4$ to $\pi / 2[51]$

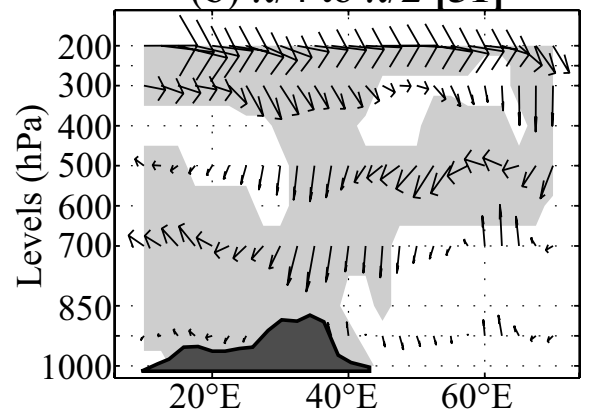

(c) $\pi / 2$ to $3 \pi / 4[71]$

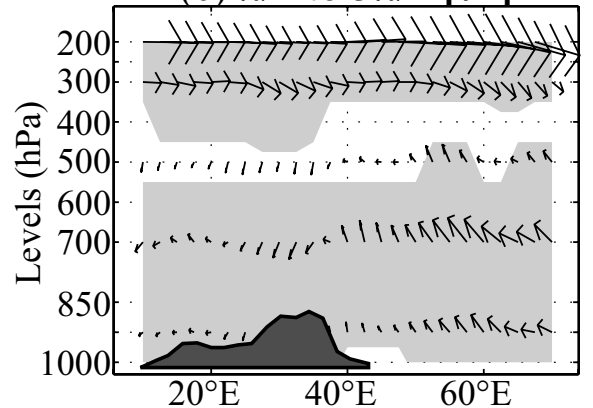

(d) $3 \pi / 4$ to $\pi[36]$

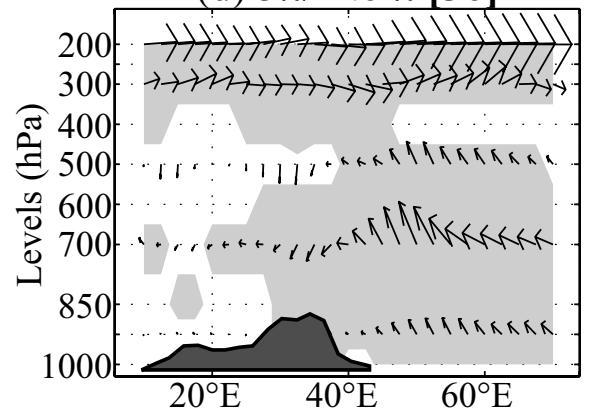

(e) $\pi$ to $5 \pi / 4[35]$

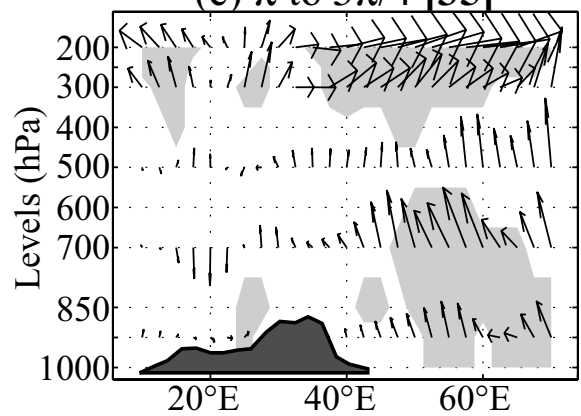

(f) $5 \pi / 4$ to $3 \pi / 2[56]$

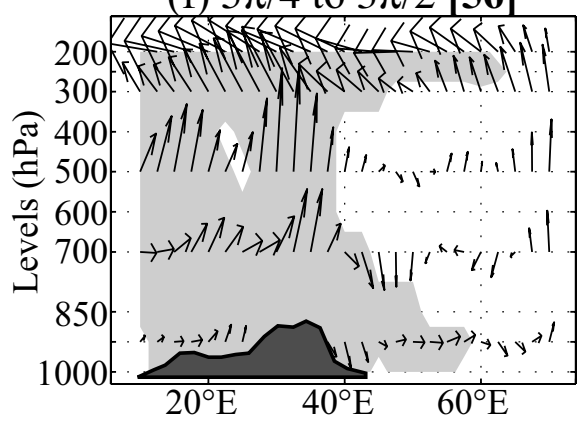

(g) $3 \pi / 2$ to $7 \pi / 4[58]$

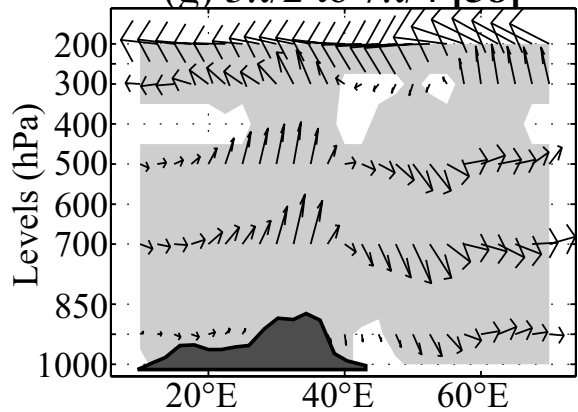

(h) $7 \pi / 4$ to $2 \pi[60]$

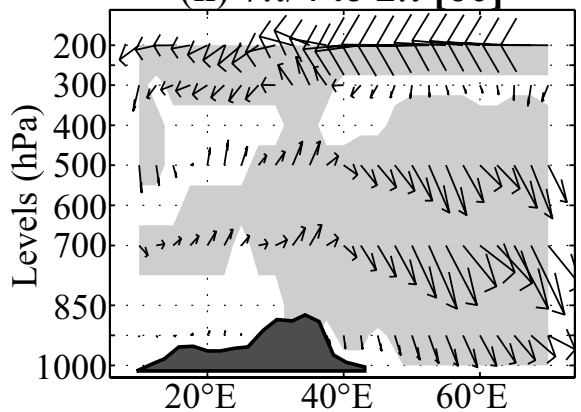

Figure 8. Vertical cross-sections of the mean vertical $(w)$ and zonal $(u)$ components of the wind along the equator $\left(2.5^{\circ} \mathrm{N}-2.5^{\circ} \mathrm{S}\right.$ ) for each Madden-Julian Oscillation (MJO) phase, in bins: (a) 0 to $\pi / 4$, (b) $\pi / 4$ to $\pi / 2$, (c) $\pi / 2$ to $3 \pi / 4$, (d) $3 \pi / 4$ to $\pi$, (e) $\pi$ to $5 \pi / 4$, (f) $5 \pi / 4$ to $3 \pi / 2$, (g) $3 \pi / 2$ to $7 \pi / 4$, and (h) $7 \pi / 4$ to $2 \pi$. Shaded areas show significant anomalies (after the removal of the annual cycle) using the Hotelling $t^{2}$-test (95\% level) applied to $w$ and $u$. East African topography as approximated by NCEP grids is also displayed. The number of pentads in each phase bin is indicated in bold; the total of 435 pentads represents those characterized by a moderate to high 
(a) Mean sea level pressure anomalies $\pi / 2-3 \pi / 4$

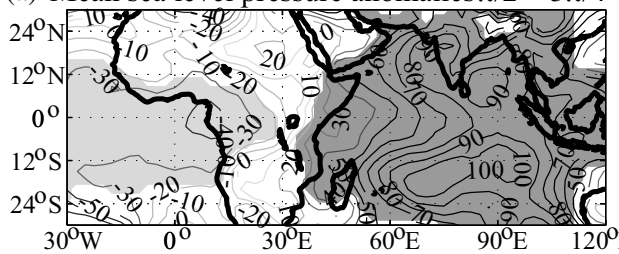

(b) Geopotential height anomalies $\pi / 2-3 \pi / 4$
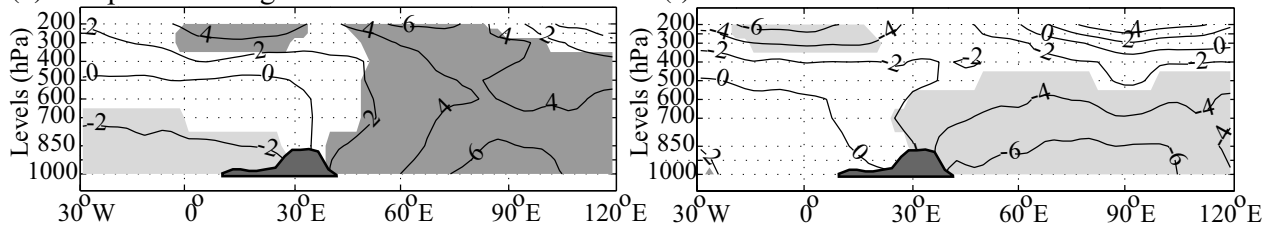

(c) $700 \mathrm{hPa}$ wind anomalies

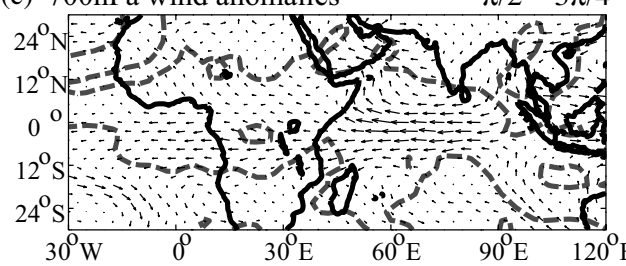

(g) $5 \pi / 4-3 \pi / 2$

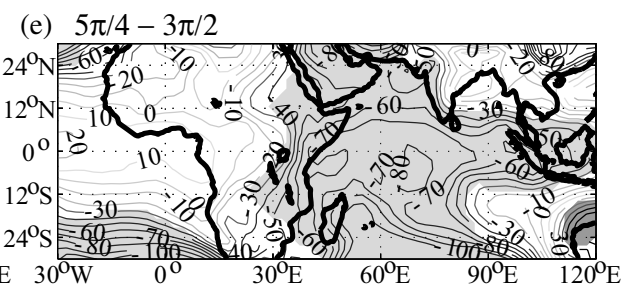

(f) $5 \pi / 4-3 \pi / 2$

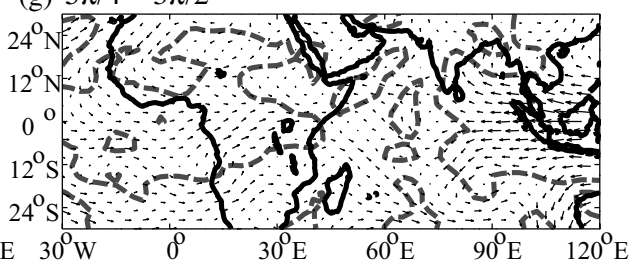

(d) OLR anomalies

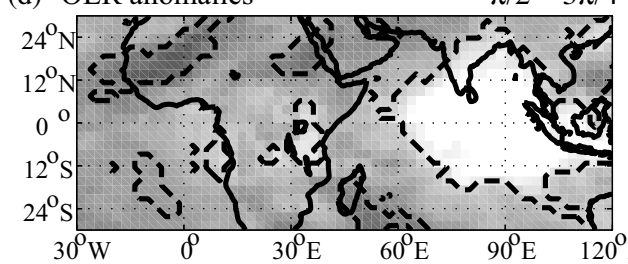

(h) $5 \pi / 4-3 \pi / 2$

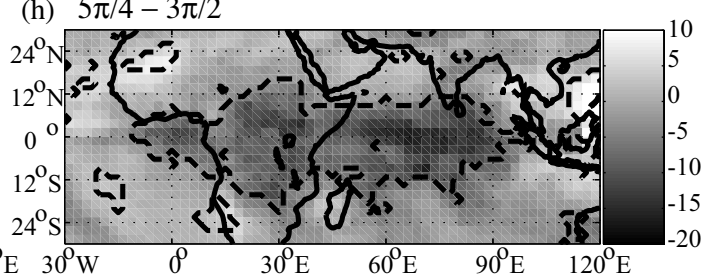

Figure 9. Mean atmospheric pattern anomalies calculated after removal of the annual cycle during MaddenJulian Oscillation (MJO) phase $\pi / 2$ to $3 \pi / 4$ : (a) Mean sea-level pressure anomalies (hPa), light (dark) grey areas denote significant negative (positive) anomalies ( $t$-test, 95\% level); (b) vertical tropospheric cross-section of geopotential height anomalies $(\mathrm{m})$ along the equator $\left(2.5^{\circ} \mathrm{N}-2.5^{\circ} \mathrm{S}\right)$, significance tested and displayed as in (a); (c) $700 \mathrm{hPa}$ wind anomalies $\left(\mathrm{m} \mathrm{s}^{-1}\right.$ ), dashed lines encompass significant anomalies (Hotelling $t^{2}$-test, $95 \%$ level); (d) outgoing long-wave radiation (OLR) anomalies $\left(\mathrm{W} \mathrm{m}^{-2}\right)$, dashed lines encompass significant anomalies ( $t$-test, 95\% level), key on right-hand side; (e) to (h) are as (a) to (d), respectively, but for MJO phase $5 \pi / 4$ to $3 \pi / 2$.

The wet conditions found in coastal EEA based on rain-gauge data are, therefore, puzzling. MSLP (Fig. 9(a)) and lower-layer geopotential height anomalies (Fig. 9(b)) both exhibit strong zonal gradients along the equator. MSLP is then abnormally low in the west of the domain (Gulf of Guinea and Congo basin) and abnormally high in the east (Indian Ocean and EEA seashore). The EEA Highlands act as a barrier between these two consistent-anomaly areas. The strong resulting east-west gradient accounts for low-level easterly wind anomalies between the central Indian Ocean and the Gulf of Guinea (Figs. 8(c) and 9(c)). They may induce enhanced moisture advection over the East African coast from the equatorial Indian Ocean. Over the western Indian Ocean/EEA coast, the null or weakly positive OLR anomalies observed at this phase (Fig. 9(d), with an average of $259 \mathrm{~W} \mathrm{~m}^{-2}$ over the east region, Fig. 7(b)) suggest the absence of cold-top convective clouds. This is confirmed by the fact that upward-motion anomalies do not reach the upper troposphere (Fig. 8(c)). 
Given these OLR and circulation anomaly patterns, two hypotheses can be formulated for the origin of the rainfall peak along the coast.

- Relatively shallow convection. Johnson et al. (1999) found that cumulus congestus contributed to a significant fraction of tropical rainfall. The low- to mid-level upward anomalies found over the Indian Ocean at the time of the rainfall peak on the EEA coast might hint at the occurrence of such moderately developed convective processes. Note that Johnson et al. (1999) found that in the western Pacific area the three convective types they identified (namely: shallow cumulus, cumulus congestus and cumulonimbus) varied significantly on the MJO time-scale. More recently Kiladis et al. (2005) confirmed their findings.

- Stratiform rainfall. The rainfall peak found at this time along the coast may also have a stratiform origin, and correspond to very local rain-producing processes. Menz (1997) noted that precipitation in the coastal areas originated principally in relatively low-altitude cloud systems. Elsewhere in the lowland eastern regions, cumulonimbus clouds do not always induce precipitation at the ground, due to the deep layer through which any rain falls with associated evaporation; Menz (1997) found that the inclusion of a convective-stratiform algorithm to estimate rainfall resulted in much better results than algorithms based on cold-cloud only. Based on TRMM* radar data, stratiform precipitation was found to constitute a large part of rain amounts over the tropical oceans (over $40 \%$ ), including most of the Indian Ocean, while it is in the range 20-35\% over the African continent (Schumacher and Houze 2003). Such a hypothesis is also consistent with the observation of spells of very heavy rain during the 1997 short rains in the coastal region, seen to have occurred without any development of cold-top convective clouds (Okoola, personal communication). It is suggested that such precipitation events from stratiform cloud, possibly mixed with shallow convection, are more likely to occur at these phases of the MJO in relation to the lower-layer easterly anomalies recorded over the Indian Ocean. However, they still constitute only a fraction of total rainfall. Other wet spells might be associated with deep convective events, which would be more directly reflected in the OLR data at other phases of the MJO cycle.

Focus now turns to the second key MJO phase, from $5 \pi / 4$ to $7 \pi / 4$, which displays positive rainfall anomalies in the Highlands but weakly negative anomalies on the coast. MSLP and geopotential height anomalies (see the example for phase $5 \pi / 4$ to $3 \pi / 2$ in Figs. 9(e) to (h)) exhibit almost opposite patterns to those obtained for phases $\pi / 2$ to $\pi$, with low pressure located over EEA and the nearby Indian Ocean. The strongest low-level pressure gradient between the Atlantic and Indian Ocean longitudes is again located over the Highlands. This gradient is the cause of the lower-layer westerly anomalies noted for this phase over Central Africa (Figs. 8(f) and (g), and 9(c)). Westerly anomalies are known to be favourable for wet spells in EEA (Nakamura 1968; Vincent et al. 1979; Anyamba 1984; Minja 1985) but their origin has never been clearly established. It is suggested that they may arise from large-scale changes in the pressure gradient between the Indian and Atlantic Oceans, and partly phaselocked on the MJO cycle. The resulting low-level moisture influx from the Congo basin and Atlantic Ocean fuels deep convection. This is in agreement with the strong upward-motion anomalies (Fig. 8(f)) and the OLR signal (Fig. 9(h)). Deep convection is also triggered by upper easterly anomalies, and the whole pattern denotes a cellular circulation along the equator between the Atlantic Ocean and the EEA Highlands. These features confirm the convective nature of the rain spells found at this stage in the west region. 


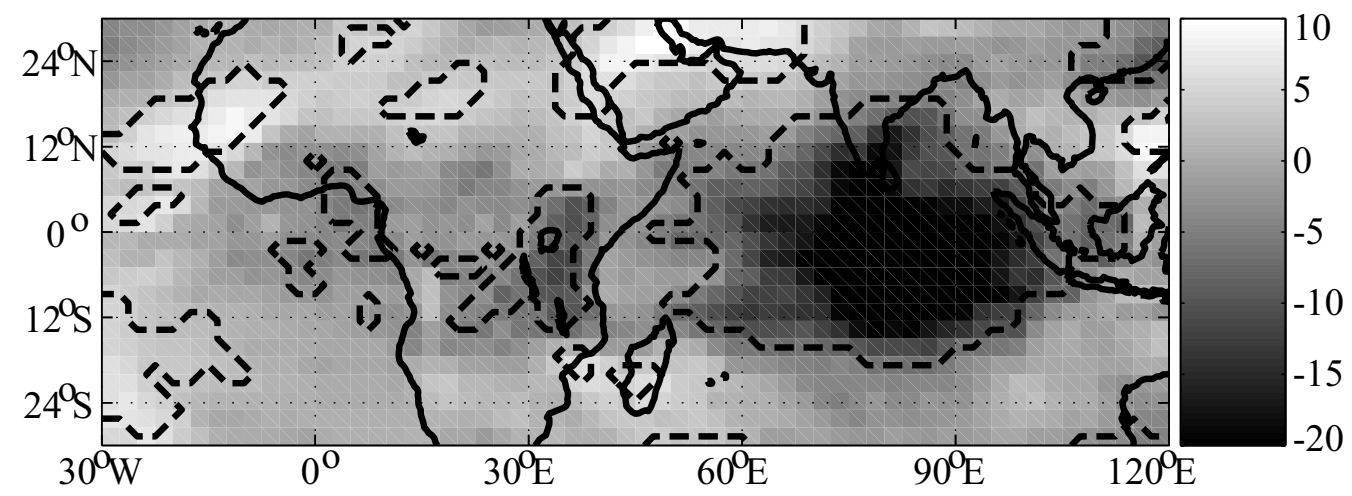

Figure 10. Mean outgoing long-wave radiation anomalies $\left(\mathrm{W} \mathrm{m}^{-2}\right)$ with seasonal variations removed at Madden-Julian Oscillation phase $3 \pi / 2$ to $7 \pi / 4$. Dashed lines encompass significant anomalies ( $t$-test, $95 \%$ level).

As shown in Fig. 7(a), these wet conditions persist for quite a long time. Figure 10 presents the OLR anomalies at the next MJO phase ( $3 \pi / 2$ to $7 \pi / 4)$. While they rapidly come close to zero along the EEA coast (see also Fig. 7(b)) they are still markedly negative over the eastern Indian Ocean, as well as in an isolated area covering the EEA Highlands. This discontinuous pattern seems robust since it also appears in the OLR composite maps published by Matthews (2000; 12-month period), Wheeler and Hendon (2004; December to February) and Hsu and Lee (2005; November to April). The deep convection anomaly over the eastern Indian Ocean is an expression of the 'canonical' MJO (Madden and Julian 1994) and coincides with upper-level divergence (not shown). The persistence of negative OLR values over the Highlands is suggested to be a regional, indirect response to the MJO. While the main convective clusters have shifted some $45-60^{\circ}$ further east, active convection over the EEA Highlands is seen to be the consequence of the persisting westerly (easterly) anomalies in the low (upper) troposphere between 10 and $35^{\circ} \mathrm{E}$, and the associated 'secondary' circulation cell. Topography plays an important role in the maintenance of deep convection, as suggested by the location of the anomalous OLR area over the Highlands of the Great Lakes region, from northern Kenya to Lake Malawi. The whole pattern remains mostly valid at the $7 \pi / 4$ to $2 \pi$ phase, while positive OLR anomalies (suppressed convection) already develop over the western equatorial Indian Ocean (not shown). This highly persistent convection over EEA is locally associated with wet spells that last about 10 to 15 days (two to three $\pi / 4$ MJO phases). This is consistent with previous observations on the typical length of wet spells in the region (Mutai et al. 1998; Kabanda and Jury 2000; Mpeta and Jury 2001).

\section{CONCLUSIONS}

East Africa experiences marked intraseasonal rainfall variability; wet and dry spells alternate within each of the 3-month rainy seasons. The period separating two major consecutive wet/dry events generally lies between 20 and 50 days, indicating a possible implication of the MJO. The fact that the rainfall fluctuations are embedded in largescale zonal wind anomalies propagating eastward along the equator reinforces this statement.

Based on MJO indices developed by Wheeler and Hendon (2004), a composite analysis has been carried out of the atmospheric circulation (derived from the NCEP-2 
Reanalysis) and East African (Kenya and Northern Tanzania) rainfall anomalies for the various phases of the intraseasonal oscillation. After removal of the annual cycle, the western Indian Ocean and eastern Africa both appear to be influenced by the MJO. The eastward propagation and the alternation of anomalies showing ascent and subsidence over the region play a significant role in the occurrence of wet and dry events over EEA during its two rainy seasons (MAM and OND). The influence of the MJO on EEA rainfall may be seen at two different spatial scales: global and regional.

(i) At the global scale wet events in the Highland region fit in with the global cycle of the MJO, though with a substantial delay with respect to the location of the main convective centres in their eastward displacement. Abnormally abundant rainfall occurring there at this time unambiguously results from deep convective cells, as demonstrated by the significant negative OLR signal which accompanies the wet events and by the upward-motion anomalies reaching the upper troposphere. These convective spells persist over the EEA Highlands, while the large-scale patterns of upper-layer divergence and lower-layer convergence, associated with the MJO cycle, have already shifted to the eastern Indian Ocean. This small lag may be explained by the need for instability to develop in the mid-troposphere and consistent moisture advection from the west to pick up before deep convection sets in over East Africa. Several authors have found that wet spells are usually accompanied by westerly wind anomalies above East Africa (Johnson and Mörth 1960; Nakamura 1968; Camberlin and Wairoto 1997). During an MJO cycle such a pattern occurs when the main convective clusters are located over the Indian Ocean and the pressure gradient between the Indian and Atlantic oceans is reversed, leading to westerly anomalies in the middle and lower layers.

(ii) At the regional scale in addition to the above mentioned delay in the setting up of convection over the Highlands, the situation is more typically illustrated by the out-ofphase response of coastal precipitation to MJO activity. The eastern and coastal regions, facing the Indian Ocean, do not show significant rainfall anomalies at the phase of the MJO cycle corresponding to wet periods in the west. They experience a positive rainfall anomaly peak well before the ascending motion has reached the East African meridian, i.e. earlier than the western part of the EEA region. At this phase, pressure gradients between the Indian and Atlantic oceans are conducive to enhanced lowertropospheric easterlies over the region. Stronger trade winds are assumed to favour moisture advection over the land mass. The fact that at this time OLR anomalies are not significant, indicates that such coastal wet events often occur in the absence of deep convection. Together with previous observations on rain types in the region, this suggests that precipitation at this phase is likely to arise from stratiform clouds, possibly mixing with relatively shallow convective clouds.

Although this work has provided evidence that the intraseasonal oscillation has significant implications over EEA, the contribution of the MJO to the interannual fluctuation of seasonal rainfall amounts remains to be determined. It must be remembered that the MJO signal itself is characterized by a strong seasonal to interannual variability in its amplitude. In the present work only moderate to well-developed events are extracted. Consequently, the influence of the MJO on East African rainfall may vary from one season to another, and also within a given season. These aspects are considered in Part II (Pohl and Camberlin 2006). 


\section{ACKNOWLEDGEMENTS}

The authors thank Dr R. E. Okoola (University of Nairobi, Kenya) for his advice on this paper. This work was carried out as a part of the LOTI-VCI project funded by the French Programme National d'Etudes de la Dynamique du Climat (PNEDC).

Anyamba, E. K.

Barron, J., Rockstrom, J.,

Gichuki, F. and Hatibu, N.

Camberlin, P. and Okoola, R. E.

Camberlin, P. and Philippon, N.

Camberlin, P. and Wairoto, J.

Der Mégréditchian, G.

Fink, A. and Speth, P.

Gunn, B. W., McBride, J. L., Holland, G. J., Keenan, T. D., Davidson, N. E. and Hendon, H. H.

Hsu, H.-H. and Lee, M.-Y.

Johnson, D. H. and Mörth, H. T.

Johnson, R. H., Rickenbach, T. M., Rutledge, S. A.,

Ciesielski, P. E. and

Schubert, W. H.

Kabanda, T. A. and Jury, M. R.

Kalnay, E., Kanamitsu, M., Kistler, R., Collins, W., Deaven, D., Gandin, L., Iredell, M., Saha, S., White, G., Woollen, J., Zhu, Y., Chelliah, M., Ebisuzaki, W., Higgins, W., Janowiak, J., Mo, K. C., Ropelewski, C., Wang, J., Leetmaa, A., Reynolds, R., Jenne, R. and Joseph, D.

Kanamitsu, M., Ebisuzaki, W., Woollen, J., Yang, S.-K., Hnilo, J. J., Fiorino, M. and Potter, G. L.

Kiladis, G. N., Straub, K. H. and Haertel, P. T.

Knutson, T. R. and

Weickmann, K. M.

Liebmann, B. and Smith, C. A.

Madden, R. A. and Julian, P. R.

2003

2003

2005

1960

1999

2000

1996

\section{REFERENCES}

1984 On the monthly mean lower tropospheric circulation and the anomalous circulation during the 1961/62 floods in East Africa. MSc thesis, University of Nairobi, Nairobi

Dry spell analysis and maize yields for two semi-arid locations in East Africa. Agric. Forest Meteorol., 117, 23-37

The onset and cessation of the 'Tong rains' in eastern Africa and their interannual variability. Theor. Appl. Climatol., 75, 43-54

2002 The East African March-May rainy season: Associated atmospheric dynamics and predictability over the 1968-97 period. J. Climate, 15, 1002-1019

1997 Intraseasonal wind anomalies related to wet and dry spells during the 'long' and 'short' rainy seasons in Kenya. Theor. Appl. Climatol., 58, 57-69

1992 Le traitement statistique des données multi-dimensionnelles: application à la météorologie, Tome I. Ecole Nationale de la Météorologie, Toulouse, France

1997 Trimodal characteristics of tropical convection. J. Climate, 12, 2397-2418

1989 The Australian summer monsoon circulation during AMEX Phase II. Mon. Weather Rev., 117, 2554-2574

Synoptic evolution of composite wet spells over northern Tanzania. Climate Res., 15, 239-248

The NCEP-NCAR 40 year reanalyses project. Bull. Am. Meteorol. Soc., 77, 437-471

2002 NCEP-DOE AMIP II reanalysis (R-2). Bull. Am. Meteorol. Soc., 83, 1631-1643

2005 Zonal and vertical structure of the Madden-Julian Oscillation. J. Atmos. Sci., 62, 2790-2809

1987 30-60 day atmospheric oscillations: Composite life cycles of convection and circulation anomalies. Mon. Weather Rev., 115, 1407-1436

Description of a complete (interpolated) outgoing longwave radiation dataset. Bull. Am. Meteorol. Soc., 77, 1275-1277

1971 Description of a 40-50 day oscillation in the zonal wind in the tropical Pacific. J. Atmos. Sci., 28, 702-708 
Madden, R. A. and Julian, P. R.

Matthews, A. J.

Menz, G.

Minja, W. E. S.

Mpeta, E. J. and Jury, M. R.

Mutai, C. C. and Ward, M. N.

Mutai, C. C., Ward, N. and Colman, A. W.

Nakamura, K.

Pohl, B. and Camberlin, P.

Pohl, B., Camberlin, P. and Roucou, $\mathrm{P}$.

Salby, M. L. and Hendon, H. H.

Schumacher, C. and Houze, R. A.

Vincent, C. E., Davies, T. D. and Beresford, A. K. C.

Von Storch, H. and Zwiers, F. W.

Wang, B. and $\mathrm{Xu}, \mathrm{X}$.

Wheeler, M. C. and Hendon, H.

Zorita, E. and Tilya, F. F.
1972 Description of global-scale circulation cells in the tropics with a 40-50 day period. J. Atmos. Sci., 29, 1109-1123

1994 Observations of the 40-50 day tropical oscillation-A review. Mon. Weather Rev., 122, 814-837

2000 Propagating mechanisms for the Madden-Julian oscillation. Q. J. R. Meteorol. Soc., 126, 2637-2652

2004 Intraseasonal variability over tropical Africa during northern summer. J. Climate, 17, 2427-2440

1997 Regionalization of precipitation models in East Africa using Meteosat data. Int. J. Climatol., 17, 1011-1027

1985 A comparative investigation of weather anomalies over East Africa during the 1972 drought and 1977-78 wet periods. MSc Thesis, University of Nairobi, Nairobi

2001 Intra-seasonal convective structure and evolution over tropical East Africa. Climate Res., 17, 83-92

2000 East African rainfall and the tropical circulation/convection on intraseasonal to interannual timescales. J. Climate, 13, 3915-3939

1998 Towards the prediction of the East African short rains based on sea-surface temperature-atmosphere coupling. Int. J. Climatol., 18, 975-997

1968 Equatorial westerlies over East Africa and their climatological significance. Geographical Reports, Tokyo Metropolitan University, 3, 43-61

2006 Influence of the Madden-Julian Oscillation on East African rainfall. II: March-May season extremes and interannual variability. Q. J. R. Meteorol. Soc., 132, 2541-2559

2005 Typology of pentad circulation anomalies over the Eastern Africa-Western Indian Ocean region, and their relationship with rainfall. Climate Res., 29, 111-127

Intraseasonal behavior of clouds, temperature, and motion in the Tropics. J. Atmos. Sci., 51, 2207-2224

2003 Stratiform rain in the Tropics as seen by the TRMM precipitation radar. J. Climate, 16, 1739-1756

1979 Recent changes in the level of lake Naivasha, Kenya, as an indicator of equatorial westerlies over East Africa. Climatic Change, 2, 175-189

1999 Statistical analysis in climate research. Cambridge University Press, Cambridge, UK

1997 Northern hemisphere summer monsoon singularities and climatological intraseasonal oscillation. J. Climate, 10, 1071-1085

2004 An all-season real-time multivariate MJO index: Development of an index for monitoring and prediction. Mon. Weather Rev., 132, 1917-1932

2002 Rainfall variability in northern Tanzania in the March to May season (long rains) and its links to large-scale climate forcing. Climate Res., 20, 31-40 